\title{
Distribusi Material Padatan Tersuspensi di Perairan Sungai Jajar, Kabupaten Demak
}

\author{
Faiz Hamzah Adriono*, Muhammad Zainuri, Muhammad Helmi, Baskoro Rochaddi \\ dan Sugeng Widada
}

\author{
Departemen Oseanografi, Fakultas Perikanan dan Ilmu Kelautan, Universitas Diponegoro \\ Jl. Prof. Sudarto, SH Tembalang Tlp. / Fax. (024)7474698 Semarang 50275 \\ Email: *faizhamzah41@gmail.com
}

\begin{abstract}
Abstrak
Perairan sekitar muara Sungai Jajar merupakan jalur keluar masuknya perahu nelayan yang bersandar di hilir sungai dan sekaligus tempat berlindung perahu dari gelombang. Daerah Aliran Sungai (DAS) Jajar yang berupa area pemukiman dan persawahan menjadikan kandungan material padatan tersuspensi di muara cukup tinggi. Faktor hidro oseanografi seperti arus dan pasang surut merupakan faktor penting dalam persebaran material padatan tersuspensi . Tujuan dilakukannya penelitian ini adalah untuk mengetahui pengaruh arus dan pasang surut terhadap sebaran material padatan tersuspensi di muara Sungai Jajar. Metode yang digunakan adalah kuantitatif dengan metode pemodelan hidrodinamika 2D menggunakan software MIKE 21. Penentuan titik sampling dilakukan menggunakan metode purposive, sedangkan pengolahan data arus dilakukan data pasang surut menggunakan metode Admiralty. Analisis material sedimen tersuspensi menggunakan metode Gravimetri. Hasil pengolahan data menunjukkan arus bergerak dari arah barat laut ke tenggara saat pasang menuju surut dengan kecepatan tertinggi 0,1972m/det dan dari arah tenggara ke barat laur saat surut menuju pasang dengan kecepatan tertinggi $0,128 \mathrm{~m} / \mathrm{det}$. Arus saat pasang menuju surut membawa sedimen tersuspensi dari muara sungai ke arah laut dan saat arus surut menuju pasang sedimen tersuspensi yang berada di laut terbawa arus menuju muara sungai. Nilai sedimen tersuspensi pada kedalaman 0,2D berkisar antara 0 0,3818-0,4435 g/l, t berkisar antara 0,3913 0,4477 g/l pada kedalaman 0.6D dan berkisar antara 0,3983-0,4690 g/l pada kedalaman 0,8D. Saat kondisi pasang menuju surut maupun surut menuju pasang konsentrasi sedimen tersuspensi di sekitar muara sungai lebih tinggi disbanding lokasi laiinya. Berdasarkan hasil penelitian dapat disimpulkan bahwa persebaran material padatan tersuspensi di lokasi dipengaruhi arah arus dan pasang surut.
\end{abstract}

Kata kunci : Material Padatan Tersuspensi, Arus, Pasang Surut, Muara sungai Jajar

\begin{abstract}
The waters around the estuary of the Jajar River are both the entry and exit to fishing boats that lean downstream and at the same time the waters around the estuary also provide shelter from the waves. The quiet amount of activities at the Jajar River estuary have an impact on the content of the suspended solids. Hydro oceanographic factors such as currents and tides are important factors in the distribution of suspended solids. The purpose of this research is to determine the effect of the currents and tides on the distribution of the suspended solids at the site. The method used in this research was quantitative with a location determination method using a purposive sampling method. The current data processing was carried out with 2D hydrodynamics using MIKE 21 software. The tidal data was processed using the Admiralty method. The Gravimetric method was used to analyze the suspended sediment material. The results of field data processing show that the current moves from the southwest to the northeast at high tide to recede with a maximum speed of $0,1972 \mathrm{~m} / \mathrm{s}$ and from the northeast to the southwest at recede to high tide with a maximum speed of 0,128 m/s Current that happened due to high tide to recede brought suspended sediments from river estuary drifted towards the sea and when current happened due to receding to high tide suspended sediments from the sea towards the river estuary. The suspended sediment values ranged from $0,3818-0,4435 \mathrm{~g} / \mathrm{l}$ on $0.2 \mathrm{D}$ ranged from $0,3913-0,4477 \mathrm{~g} / \mathrm{l}$ on $0.6 \mathrm{D}$ and $0,3983-$ $0,4690 \mathrm{~g} / \mathrm{l}$. on $0.8 \mathrm{D}$. When high tide to recede or even recede to high tide, the highest sediment concentrations are at the mouth of the river. Based on the results of this research it can be concluded that the distribution of suspended solids in the location are affected by currents direction and tides.
\end{abstract}

Keywords : : Suspended Solids, Current, Tides, Jajar Estuary 


\section{PENDAHULUAN}

Demak merupakan salah satu Kabupaten pesisir di Indonesia. Demak memiliki luas perairan sebesar $252,34 \mathrm{~km}^{2}$ dan memiliki Panjang garis pantai sebesar panjang garis pantai 72,14 km yang membentang dari wilayah Kecamatan Sayung sampai Kecamatan Wedung. Pesisir Demak dimanfaatkan masyarakat untuk berbagai aktifitas masyarakat sebagai pelabuhan dan juga aktifitas perikanan. beberapa sungai demak juga di fungsikan sebagai buangan limbah industri maupun limbah rumah tangga. Selain itu demak memiliki beberapa sungai yang mengalir ke pesisir seperti sungai Tuntang, sungai Gendong dan sungai Jajar. Sungai jajar terletak di Desa Morodemak, Demak Jawa Tengah. Muara sungai jajar terdapat pelabuhan perikanan tingkat provinsi dan juga digunakan untuk beberapa kegiatan perikanan. Sungai jajar berulu pada pegunungan kandeng utara. Pada aliran Sungai jajar membawa material pasir dan lumpur. Material tersebut disebabkan erosi yang terjadi pada daratan maupun aliran sungai sendiri. Hal tersebut menyebabkan terdapatnya material padatan tersuspensi pada muara sungai jajar.

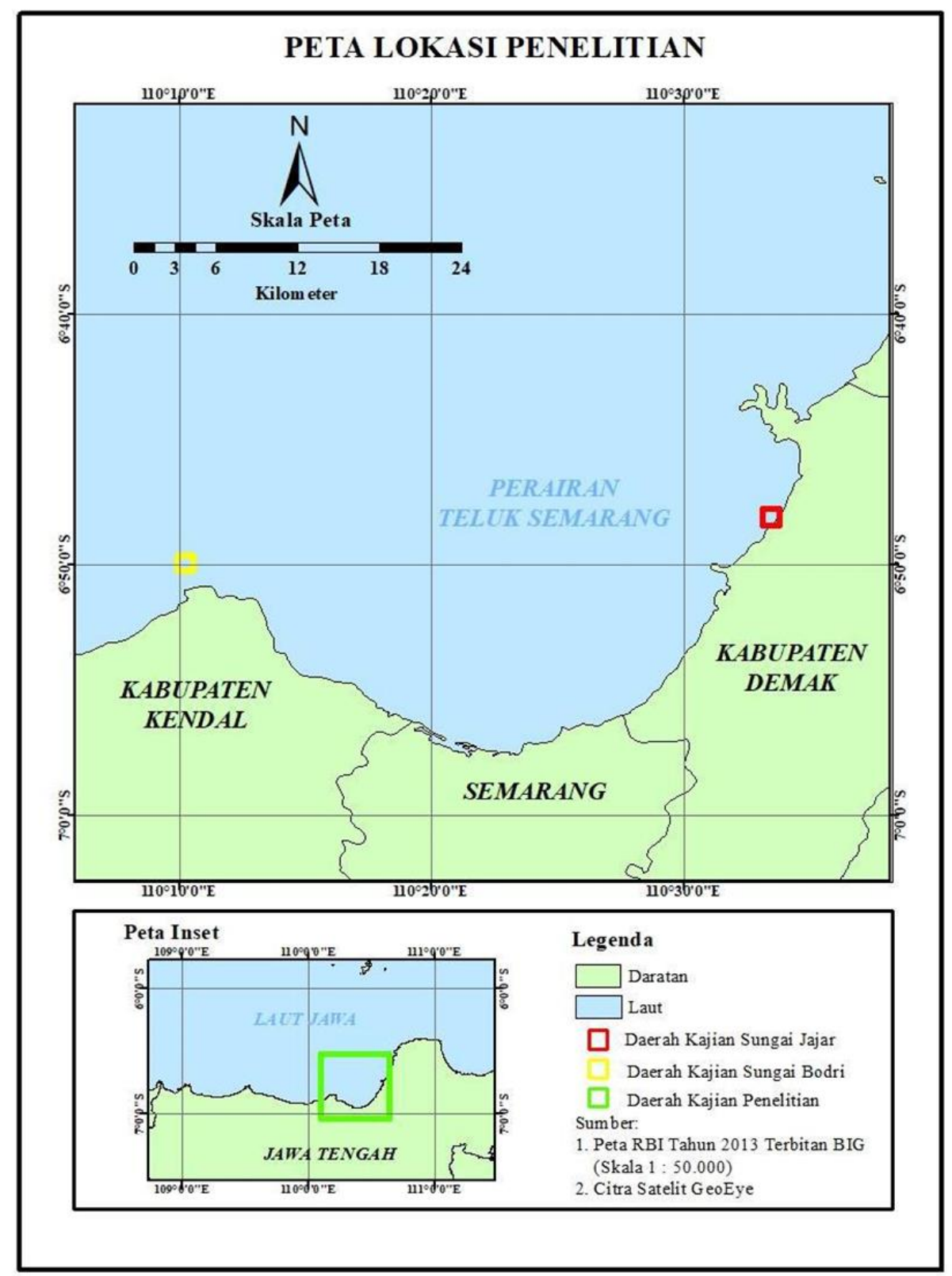

Gambar 1. Peta Lokasi Penelitian 
Material Padatan Tersuspensi dikenal pula dengan sebutan suspended sediment load atau suspended particulate material. MPT adalah partikel-partikel yang melayang dalam air, terdiri dari komponen hidup dan komponen mati. Komponen hidup terdiri dari fitoplankton, bakteri, fungi, dan sebagainya. Sedang komponen mati terdiri dari detritus dan partikel - partikel anorganik (Ariandi,1997). Secara umum sumber - sumber material tersuspensi yang dapat berasal dari aliran sungai berupa hasil pelapukan, material darat, oksihidroksida, dan bahan pencemar dari atmosfer berupa debu - debu atau abu yang melayang; dari laut berupa sedimen anorganik yang terbentuk dilaut, dan sedimen biogenous dari sisa rangka organisme dan bahan organik lainnya; serta dari estuari berupa hasil flokulasi, presipitasi sedimen dan produksi biologis organisme estuari (Chester, 1990).

Daerah muara Sungai memiliki banyak kegiatan masyarakat. Kegiatan tersebut seperti aktifitas perikanan Aktifitas kapal ikan yang digunakan masyarakat yang lalu lalang juga mengakibatkan terangkatnya material padatan tersuspensi. Selain itu, sungai jajar banyak digunakan untuk pembuangan padatan tersuspensi dari pembuagan limbah industri maupun limbah rumah tangga. Hal ini juga mempengaruhi tingkat kualitas peariran yang juga berpengaruh terhadap tangkapan ikan di perairan. Arus pasang surut juga berpengaruh pada sebaran material padatan tersuspensi pada perairan. Pengambilan sampel air untuk penelitian ini tersebar pada 9 titik lokasi di perairan muara sungai jajar. Berdasarkan kondisi tersebut sehingga perlu adanya permasalahan yang dibagi dalam penelitian ini. Sebaran MPT dan konsentrasi Berdarkan 3 kedalaman yang berbeda yaitu 0,2D; 0,6D; dan 0,8D. Berdasarkan penjelasan di atas penelitian ini dilakukan untuk mengetahui persebaran dari konsentrasi material padatan tersuspensi pada perairan muara sungai Jajar, Demak, Jawa Tengah.

\section{MATERI DAN METODE Materi Penelitian}

Materi yang digunakan dalam penelitian ini adalah data lapangan (data primer) dan data-data pendukung dari instansi terkait (data skunder). Data primer yang digunakan adalah data Material Padatan Tersuspensi di perairan sekitar muara Sungai Kalijajar Kabupaten Demak. Sedangkan untuk data sekunder yang digunakan adalah data pasang surut, data arus permukaan dan peta Rupa Bumi Indonesia dengan skala $1: 250.000$.

\section{Metode Penelitian}

Metode yang digunakan dalam penelitian yaitu metode kuantitatif. Sugiyono (2009) menjelaskan bahwa, metode kuantitatif adalah pengumpulan data menggunakan instrumen penelitian serta data yang sudah didapat diolah menjadi bentuk angka. Metode ini umumnya digunakan dalam penelitian populasi dan sampel tertentu. Pengambilan data MPT di muara Sungai Kalijajar Kabupaten Demak menggunakan metode kuantitatif untuk mengetahui tingkat konsentrasi MPT.

\section{Metode Penentuan Lokasi}

Penelitian ini dilakukan di muara sungai Jajar Demak Jawa Tengah. Penentuan lokasi titik sampling ini menggunakan purposive sampling methode. Penentuan lokasi pengambilan sampel penelitian dilakukan berdasarkan kondisi yang diharapkan dapat mewakili kondisi secara keseluruhan daerah yang diteliti. Stasiun 1 sampai 3 diharapkan mewakili muara sungai, kemudian stasiun 4 sampai 6 mewakili perairan yang masih dipengaruhi oleh muara, sedangkan stasiun 7 sampai 9 mewakili laut lepas. Dalam penelitian ini menggambarkan pengaruh pasang surut dan arus terhadap sebaran material padatan tersuspensi di daerah yang diteliti.

\section{Metode Pengambilan Data Pengambilan Sampel Air}

Pada penelitian ini pengambilan sampel air laut dari suatu kolom perairan pada 9 stasiun pengamatan. Pengambilan contoh dapat dilakukan secara sesaat dengan menggunakan trap atau botol sampler. Teknik pengambilan seperti ini disebut sebagai teknik pengukuran langsung atau direct sampling (Poerbandono dan Djunasjah, 2005) 


\section{Pengambilan Data Pasang Surut}

Pengambilan data pasang surut diambil dari web Badan Informasi Geospasial, http://inasealevelmonitoring.big.go.id/ dan diinterpolasi dengan data yang diambil dari aplikasi MIKE 21 untuk peramalan Pasang Surut. Pengambilan data pasang surut ini akan digunakan untuk mengetahui kondisi pasang surut pada perairan dan menentukan tipe pasang surutnya.

\section{Metode Pengolahan dan Analisa Data}

\section{Pengolahan Data Sampel Material Padatan Tersuspensi}

Analisa MPT menggunakan metode gravimetri agar didapatkan nilai material padatan tersuspensi pada tiap stasiun. Metode gravimetri dapat digunakan untuk menentukan residu tersuspensi yang terdapat dalam sampel air (Badan Standarisasi Nasional, 2008). Perhitungan konsentrasi material padatan tersuspensi menurut Alaerts dan Santika (1984) menggunakan rumus sebagai berikut:

$$
M P T=\frac{(a-b)}{c} \mathrm{gram} / \text { liter }
$$

Keterangan:

MPT $=$ Material padatantersuspensi $(\mathrm{gram} / \mathrm{ml})$

$\mathrm{a}=$ Berat kertas saring dan berat MPT di kertas saring (gram)

$\mathrm{b}=$ Berat kertas saring (gram)

$\mathrm{c}=$ Volume sampel air $(\mathrm{ml})$

\section{Pengolahan Data Pasang Surut}

Data pasang surut diolah dengan metode admiralty untuk mendapatkan komponen pasut dan nilai Formzhal . Hasil pengolahan data dengan metode admiralty adalah besarnya amplitudo (A) dan beda fase (g) untuk 9 komponen pasang surut M2, S2, N2, K1, O1, M4, MS4, dan P1 serta S0 muka air lau rata-rata. Komponen pasang surut tersebut dapat digunakan untuk mencari kedudukan muka air laut yaitu MSL, HHWL, dan LLWL (Djaja, 1987).

\section{HASIL DAN PEMBAHASAN}

\section{Pasang Surut}

Hasil pengolahan data pasang surut ditunjukan pada Tabel 1. Berdasarkan nilai komponen-komponen pasang surut di Perairan Sungai Jajar Demak pada Tabel 1, didapatkan nilai Formzahl sebesar 1,932, dengan demikian tipe pasang surut perairan Sungai Jajar Demak tergolong tipe campuran condong ke harian tunggal dengan fenomena satu hari terjadi satu pasang tinggi dan rendah. Grafik pasang surut Perairan Sungai Jajar Demak dapat dilihat pada Gambar 2.

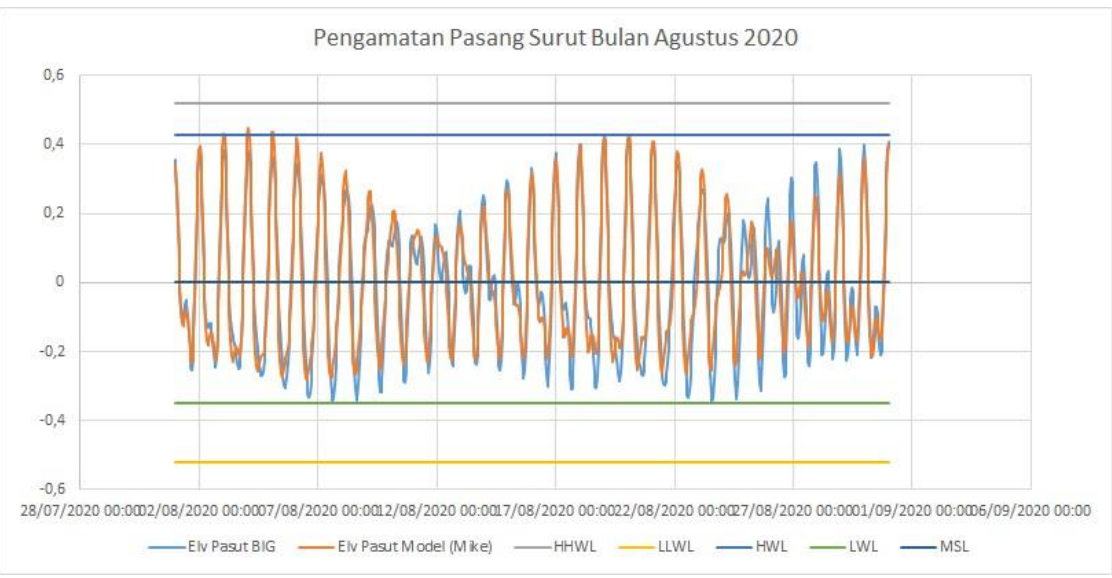

Gambar 2. Grafik Pengamatan Pasang Surut 
Tabel 1. Pengolahan Data Pasang Surut

\begin{tabular}{ccc}
\hline Komponen & Amplitudo (cm) & Beda Fase $\left(^{\circ}\right)$ \\
\hline S0 & 189.88 & 0 \\
\hline M2 & 7.47 & 357.63 \\
\hline S2 & 7.13 & 305.07 \\
\hline N2 & 2.87 & 292.36 \\
\hline K1 & 23.35 & 247.94 \\
\hline O1 & 7.80 & 95.24 \\
\hline M4 & 0.66 & 18.15 \\
\hline MS4 & 0.43 & 272.08 \\
\hline K2 & 1.93 & 305.07 \\
\hline P1 & 7.70 & 247.94 \\
\hline
\end{tabular}

\section{Kecepatan dan Arah Arus}

Hasil perhitungan arah dan kecepatan arus pada saat surut menuju pasang menggunakan pemodelan MIKE 21 menunjukkan nilai kecepatan arus maksimum pada kondisi pasang menuju surut sebesar 0,299 m/s, sedangkan nilai kecepatan maksimum pada kondisi surut menuju pasang sebesar $0,128 \mathrm{~m} / \mathrm{s}$. Nilai kecepatan arus minimum pada kondisi pasang menuju surut sebesar $0,0206 \mathrm{~m} / \mathrm{s}$, sedangkan nilai kecepatan minimum pada kondisi surut menuju pasang sebesar $0,0150 \mathrm{~m} / \mathrm{s}$.

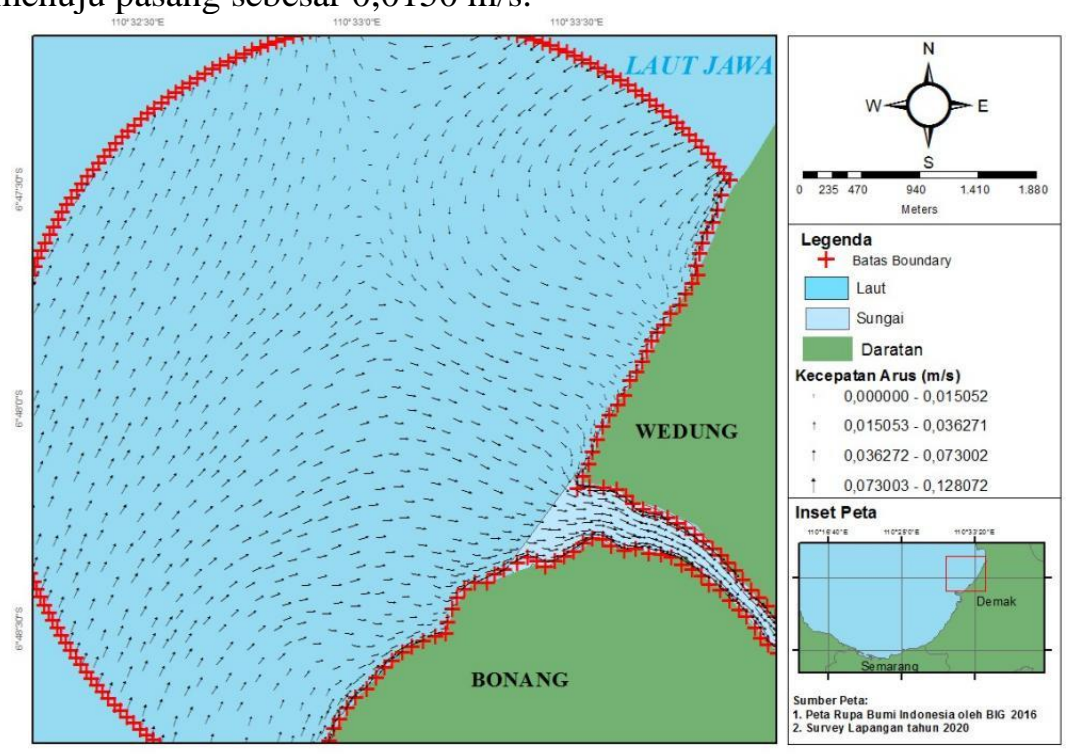

Gambar 3. Peta Pola Arus Saat Surut Menuju Pasang

Pada saat pasang menuju surut arus mendorong MPT dari daratan tersebaran menuju ke arah laut (Gambar 4). Kecepatan arus tertinggi pada kondisi pasang menuju surut berada pada stasiun 1 sampai stasiun 3 dimana lokasi ini berada di sekitar muara. MPT terkumpul pada stasiun 2 yang berada di muara sungai karena kedalaman perairan yang dangkal menghambat proses penyebaran menuju laut. Pada saat surut menuju pasang persebaran MPT menjauhi laut dan menyebar ke arah sekitar muara sungai (Gambar 3). MPT terkumpul pada stasiun stasiun 2 (muara sungai), serta stasiun 2 dan 3 (daerah laut yang masih dipengaruhi muara sungai). Arah arus saat kondisi surut menuju pasang yaitu dari barat laut menuju ke arah tenggara, sehingga pergerakan MPT menuju ke arah tenggara yaitu ke arah muara sungai. Sedangkan saat kondisi pasang menuju surut arah arus yaitu dari tenggara ke arah barat laut. Sehingga pergerakan konsentrasi MPT ke arah laut lepas. 


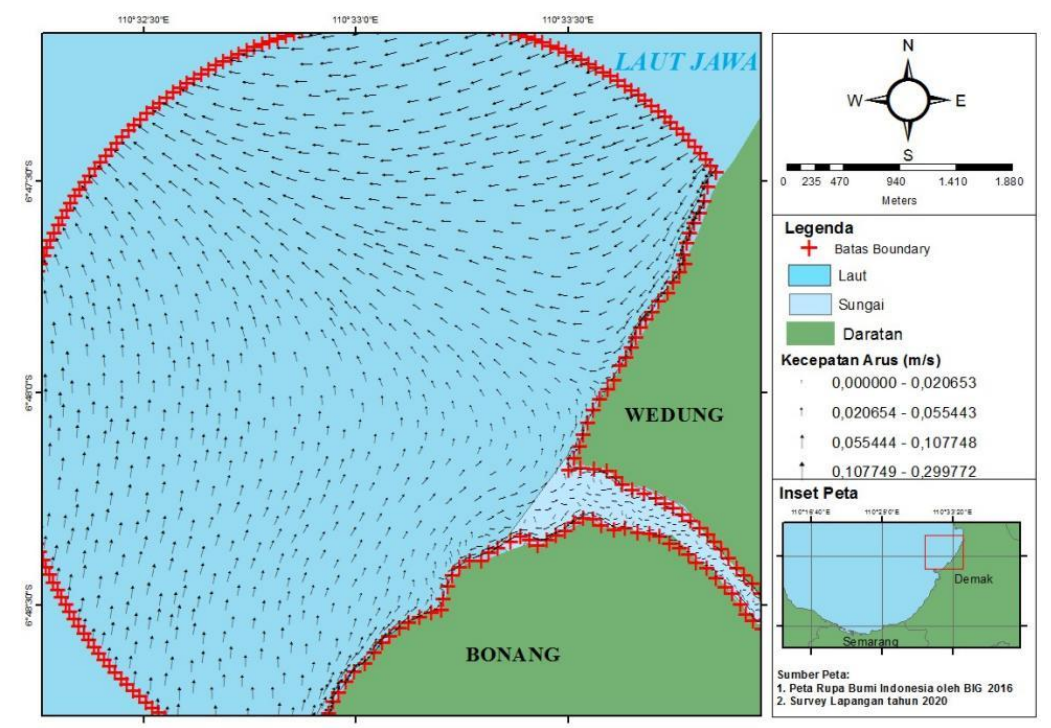

Gambar 4. Peta Pola Arus Saat Pasang Menuju Surut
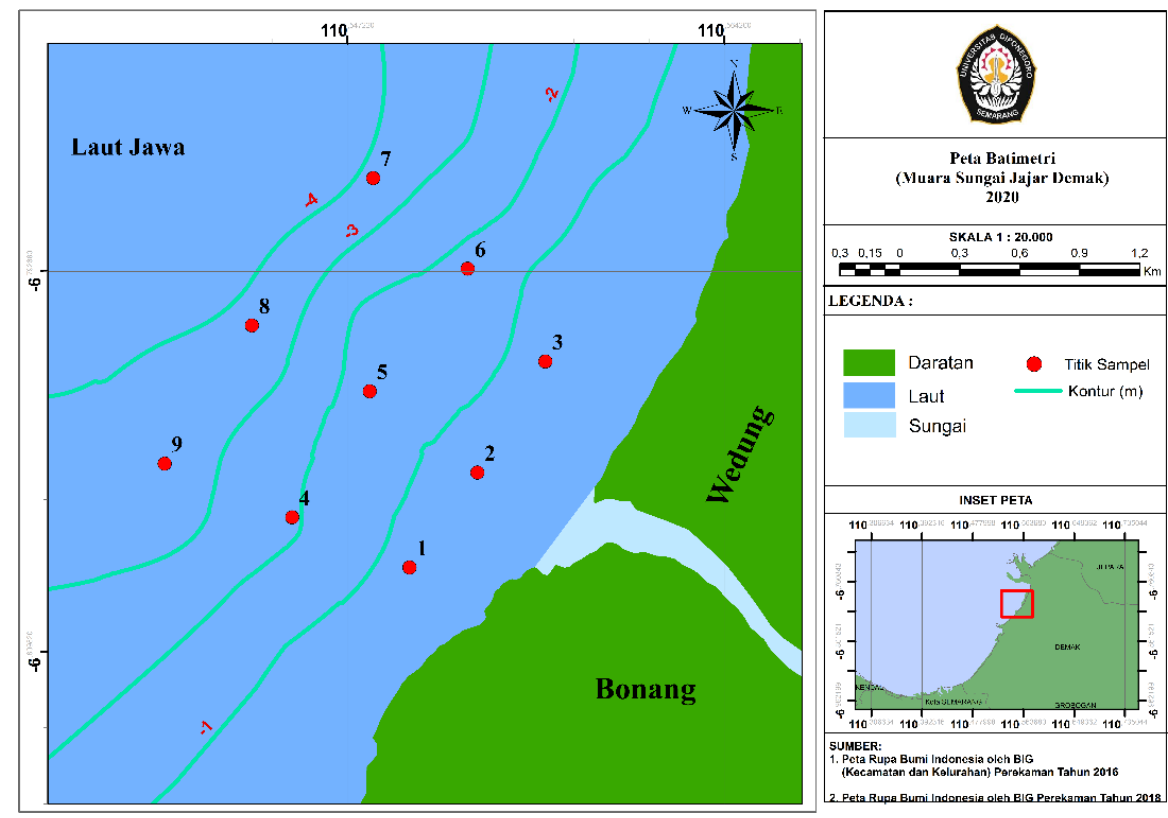

Gambar 5. Peta Peta Batimetri Muara Sungai Jajar Demak

Berdasarkan hasil penelitian, terlihat bahwa arus mempengaruhi pola sebaran MPT di perairan sekitar Muara Sungai Jajar Demak. Kecepatan dan arah arus membantu terjadinya persebaran MPT pada perairan. Saat nilai kecepatan arus besar, MPT terbawa mengikuti arah arus. Namun selain itu konsentrasi MPT dipengaruhi oleh letak stasiun, di mana semakin jauh dari sumber MPT dalam hal ini sungai Jajar Demak maka nilai konsentrasi MPT rendah dan sebaliknya nilai konsentrasi MPT semakin tinggi ketika berada di dekat sumber MPT, yaitu Sungai Jajar Demak. Terbukti nilai konsentrasi MPT tertinggi terletak pada stasiun 2. Tingginya nilai konsentrasi MPT pada stasiun 2 disebabkan pada stasiun tersebut mendapatkan suplai MPT terbanyak dibanding stasiun lainnya karena dekat dengan daratan dan konsentrasi MPT akan cenderung tinggi di dekat sumbernya, yaitu muara sungai. Nilai kecepatan yang relatif besar pada stasiun 4,5,6,7,8,9 yaitu sekitar $0,2997 \mathrm{~m} / \mathrm{s}-0,1077 \mathrm{~m} / \mathrm{s}$, membantu mendorong proses tersebarnya MPT dari laut menuju darat. Sesuai dengan pernyataan Solihuddin (2011) bahwa arus laut yang terjadi yang disebabkan oleh pasang surut maupun gelombang merupakan salah satu parameter yang mempengaruhi sebaran MPT di suatu perairan karena 
keberadaan MPT melayang di kolom perairan, sehingga pergerakan MPT dipicu oleh arah arus. Nilai konsentrasi MPT ini dipengaruhi oleh pergerakan arus dalam hal ini yaitu kecepatan dan arah arus. Sehingga semakin tinggi nilai kecepatan arus maka semakin besar pula terjadinya kekeruhan yang berpotensi menyebabkan pendangkalan. Sarjono (2009) menyatakan bahwa lokasi muara sungai yang dipengaruhi oleh arus dan pasang surut yang tinggi menyebabkan terjadinya proses pengadukan sedimen dasar yang berada di perairan dimana hal ini menunjang adanya peningkatan nilai kekeruhan di perairan.

\section{Sebaran Material Padatan Tersuspensi}

Berdasarkan hasil penelitian nilai konsentrasi MPT di perairan Muara Sungai Jajar Demak pada saat pasang menuju surut terdapat 9 stasiun. Pada kedalaman 0,2 D berkisar antara 0,3818-0,4438 g/l. Sedangkan pada kedalaman 0,6 D berkisar antara 0,3913-0,4478 g/l. Sedangkan pada kedalaman 0,8 D berkisar antara 0,3983-0,4691 g/l. Nilai konsentrasi MPT pada tiap stasiun dapat dilihat pada Tabel 2 - Tabel 4. Sebaran nilai konsentrasi muatan padatan tersuspensi disajikan dalam Gambar 6,7, dan 8.

Tabel 2. Nilai Konsentrasi MPT di Perairan Tayu pada Kondisi Pasang Menuju Surut 0,2 D

\begin{tabular}{cccc}
\hline Stasiun & Latitude & Longitude & Konsentrasi MPT(g/l) \\
\hline 1 & $06^{0} 48^{\prime} 22.90^{\prime \prime} \mathrm{LS}$ & $110^{0} 32^{\prime} 49.27^{\prime \prime} \mathrm{BT}$ & 0,4272 \\
\hline 2 & $06^{0} 48^{\prime} 02.58^{\prime} \mathrm{LS}$ & $110^{0} 33^{\prime} 01.56^{\prime \prime} \mathrm{BT}$ & 0,4438 \\
\hline 3 & $06^{0} 47^{\prime} 38.14^{\prime \prime} \mathrm{LS}$ & $110^{0} 33^{\prime} 12.61^{\prime \prime} \mathrm{BT}$ & 0,4371 \\
\hline 4 & $06^{0} 48^{\prime} 11.62^{\prime \prime} \mathrm{LS}$ & $110^{0} 32^{\prime} 22.86^{\prime \prime} \mathrm{BT}$ & 0,4183 \\
\hline 5 & $06^{0} 47^{\prime} 45.90^{\prime \prime} \mathrm{LS}$ & $110^{0} 32^{\prime} 38.76^{\prime \prime} \mathrm{BT}$ & 0,4251 \\
\hline 6 & $06^{0} 47^{\prime} 23.04^{\prime \prime} \mathrm{LS}$ & $110^{0} 32^{\prime} 55.88^{\prime \prime} \mathrm{BT}$ & 0,4058 \\
\hline 7 & $06^{0} 48^{\prime} 02.70^{\prime} \mathrm{LS}$ & $110^{0} 31^{\prime} 55.52^{\prime \prime} \mathrm{BT}$ & 0,3818 \\
\hline 8 & $06^{0} 47^{\prime} 30.15^{\prime} \mathrm{LS}$ & $110^{0} 32^{\prime} 14.09^{\prime} \mathrm{BT}$ & 0,4180 \\
\hline 9 & $06^{0} 47^{\prime} 02.199^{\prime} \mathrm{LS}$ & $110^{0} 32^{\prime} 38.933^{\prime} \mathrm{BT}$ & 0,3996 \\
\hline Rata-rata & & & 0,4174 \\
\hline
\end{tabular}

Tabel 3. Nilai Konsentrasi MPT di Perairan Tayu pada Kondisi Pasang MenujuSurut 0,6 D

\begin{tabular}{cccc}
\hline Stasiun & Latitude & Longitude & $\begin{array}{c}\text { Konsentrasi MPT } \\
(\mathbf{g} / \mathbf{l})\end{array}$ \\
\hline 1 & $06^{0} 48^{\prime} 22.90^{\prime \prime} \mathrm{LS}$ & $110^{0} 32^{\prime} 49.27^{\prime \prime} \mathrm{BT}$ & 0,4165 \\
\hline 2 & $06^{0} 48^{\prime} 02.58^{\prime \prime} \mathrm{LS}$ & $110^{0} 33^{\prime} 01.56^{\prime \prime} \mathrm{BT}$ & 0,4196 \\
\hline 3 & $06^{0} 47^{\prime} 38.14^{\prime \prime} \mathrm{LS}$ & $110^{0} 33^{\prime} 12.61^{\prime \prime} \mathrm{BT}$ & 0,4278 \\
\hline 4 & $06^{0} 48^{\prime} 11.62^{\prime \prime} \mathrm{LS}$ & $110^{0} 32^{\prime} 22.86^{\prime \prime} \mathrm{BT}$ & 0,4091 \\
\hline 5 & $06^{0} 47^{\prime} 45.90^{\prime \prime} \mathrm{LS}$ & $110^{0} 32^{\prime} 38.76^{\prime \prime} \mathrm{BT}$ & 0,4172 \\
\hline 6 & $06^{0} 47^{\prime} 23.04^{\prime \prime} \mathrm{LS}$ & $110^{0} 32^{\prime} 55.88^{\prime \prime} \mathrm{BT}$ & 0,3906 \\
\hline 7 & $06^{0} 48^{\prime} 02.70^{\prime \prime} \mathrm{LS}$ & $110^{0} 31^{\prime} 55.52^{\prime \prime} \mathrm{BT}$ & 0,3713 \\
\hline 9 & $06^{0} 47^{\prime} 30.15^{\prime \prime} \mathrm{LS}$ & $110^{0} 32^{\prime} 14.09^{\prime \prime} \mathrm{BT}$ & 0,4015 \\
\hline Rata-rata & $06^{0} 47^{\prime} 02.19^{\prime \prime} \mathrm{LS}$ & $110^{0} 32^{\prime} 38.93^{\prime \prime} \mathrm{BT}$ & 0,3903 \\
\hline
\end{tabular}


Tabel 4. Nilai Konsentrasi MPT di Perairan Demak pada Kondisi Pasang Menuju Surut 0,8 D

\begin{tabular}{cccc}
\hline Stasiun & Latitude & Longitude & $\begin{array}{c}\text { Konsentrasi MPT } \\
(\mathbf{g} / \mathbf{l})\end{array}$ \\
\hline 1 & $06^{0} 48^{\prime} 22.90^{\prime \prime} \mathrm{LS}$ & $110^{0} 32^{\prime} 49.27^{\prime \prime} \mathrm{BT}$ & 0,4019 \\
\hline 2 & $06^{0} 48^{\prime} 02.58^{\prime \prime} \mathrm{LS}$ & $110^{0} 33^{\prime} 01.56^{\prime \prime} \mathrm{BT}$ & 0,4291 \\
\hline 3 & $06^{0} 47^{\prime} 38.14^{\prime \prime} \mathrm{LS}$ & $110^{0} 33^{\prime} 12.61^{\prime \prime} \mathrm{BT}$ & 0,3981 \\
\hline 4 & $06^{0} 48^{\prime} 11.62^{\prime \prime} \mathrm{LS}$ & $110^{0} 32^{\prime} 22.86^{\prime \prime} \mathrm{BT}$ & 0,3968 \\
\hline 5 & $06^{0} 47^{\prime} 45.90^{\prime \prime} \mathrm{LS}$ & $110^{0} 32^{\prime} 38.76^{\prime \prime} \mathrm{BT}$ & 0,4076 \\
\hline 6 & $06^{0} 47^{\prime} 23.04^{\prime} \mathrm{LS}$ & $110^{0} 32^{\prime} 55.88^{\prime \prime} \mathrm{BT}$ & 0,3835 \\
\hline 7 & $06^{0} 48^{\prime} 02.70^{\prime \prime} \mathrm{LS}$ & $110^{0} 31^{\prime} 55.52^{\prime \prime} \mathrm{BT}$ & 0,3583 \\
\hline 9 & $06^{0} 47^{\prime} 30.15^{\prime} \mathrm{LS}$ & $110^{0} 32^{\prime} 14.09^{\prime \prime} \mathrm{BT}$ & 0,3943 \\
\hline Rata-rata & $06^{0} 47^{\prime} 02.199^{\prime} \mathrm{LS}$ & $110^{0} 32^{\prime} 38.93^{\prime \prime} \mathrm{BT}$ & 0,3791 \\
\hline
\end{tabular}

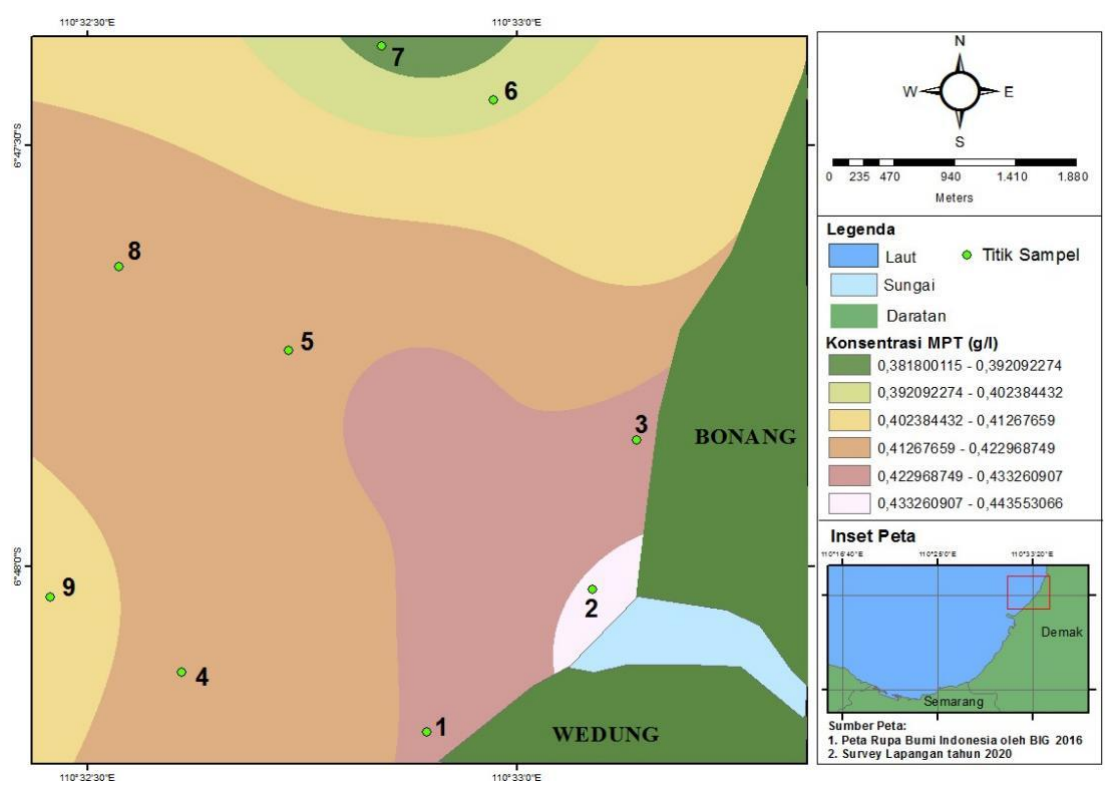

Gambar 6. Sebaran Konsentrasi MPT di Muara Sungai Jajar Demak kedalaman 0,2D 


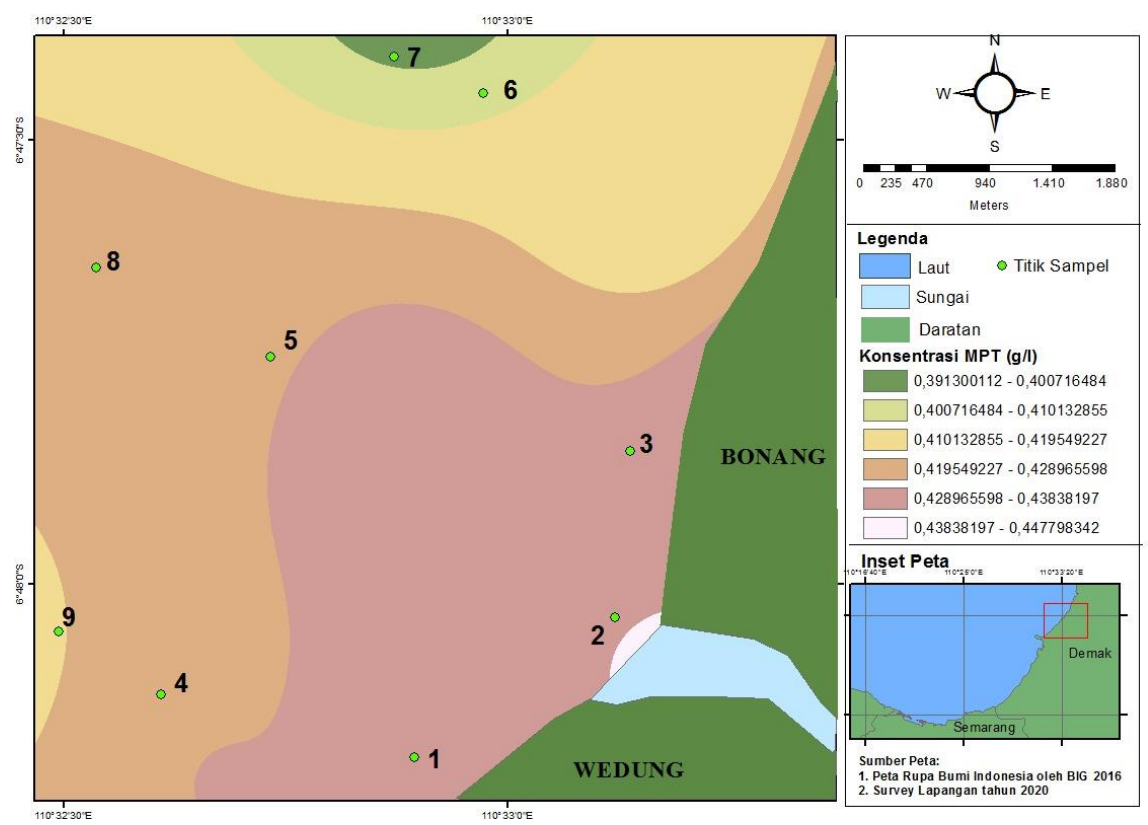

Gambar 7. Sebaran Konsentrasi MPT di Muara Sungai Jajar Demak kedalaman 0,6D

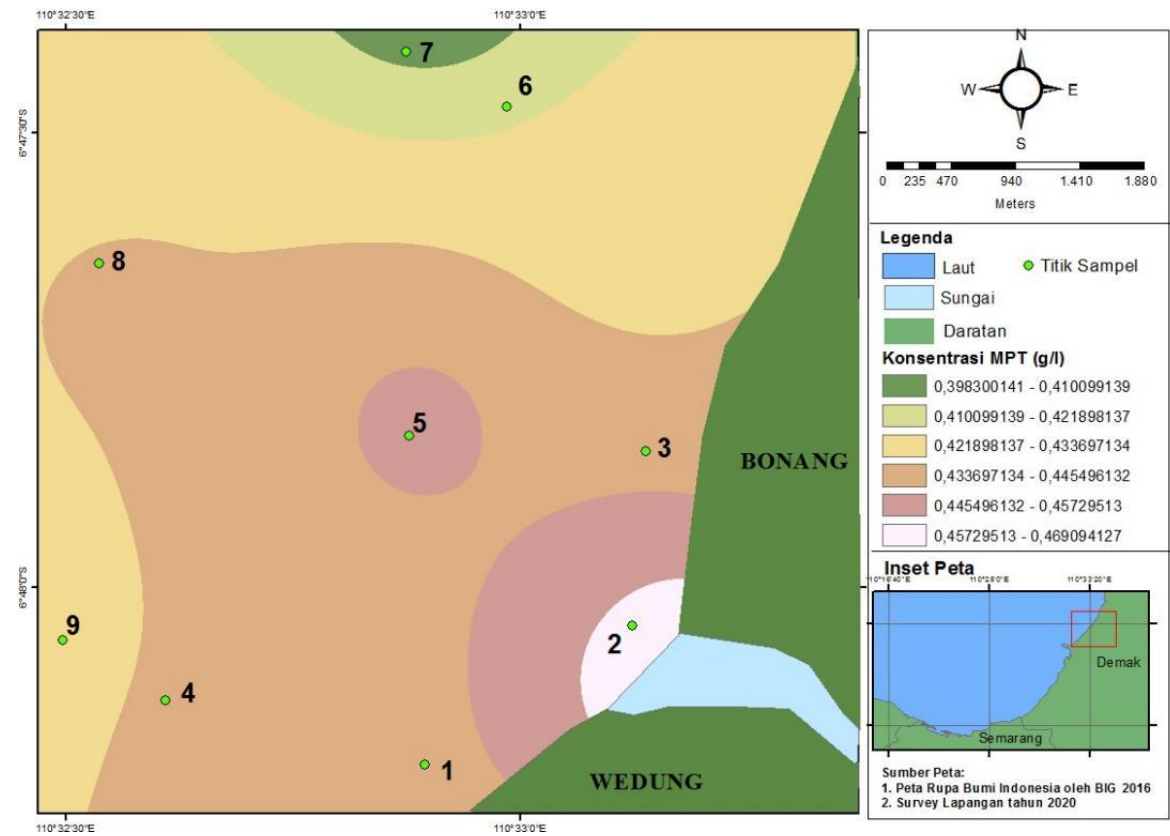

Gambar 8. Sebaran Konsentrasi MPT di Muara Sungai Jajar Demak kedalaman 0,8D

Konsentrasi MPT pada Muara Sungai Jajar Demak menunjukan nilai yang fluktuatif. Nilai konsentrasi MPT pada kedalaman 0,2D berkisar antara0,3818-0,4435 g/l, dan pada kedalaman 0,6D berkisar 0,3913 0,4477 g/l, serta pada kedalaman 0,8D berkisar antara0,3983-0,4690 g/l. Dari Gambar 6 - Gambar 8, dapat dilihat bahwa sebaran konsentrasi MPT pada kedalaman $0.8 \mathrm{D}$ lebih tinggi jika dibandingkan pada sebaran konsentrasi MPT kedalaman 0.2 D dan 0.6 D. Menurut Satriadi dan Widada (2004), hal ini disebabkan oleh adanya proses resuspensi sedimen dimana sedimen di dasar terangkat karena mengalami pengadukan oleh arus sehingga meningkatkan konsentrasi sedimen, bahwa arus dan pasang surut menyebabkan pengadukan sedimen di dasar perairan sehingga partikel sedimen tersuspensi di dalam air. Pengambilan percontoh air yang dilakukuan pada saat pasang menuju surut di mana air lebih didominasi bergerak dari darat dan tersebar ke arah laut. Namun dikarenakan kedalaman perairan pada muara yang dangkal menyebabkan terhambatnya 
proses persebaran tersebut pada perairan ini dan pada akhirnya MPT semakin meningkat serta terkumpul di sekitar muara sungai.

Hasil analisa pasang surut diperoleh bahwa tipe pasang surut di perairan sekitar Muara Sungai Jajar Demak adalah Sungai Jajar Demak tergolong tipe campuran condong keharian tunggal dengan fenomena satu hari terjadi satu pasang tinggi dan rendah. Pasang surut berpengaruh terhadap sebaran material padatan tersuspensi karena penambahan volume air dari daratan saat pasang menyebabkan konsentrasi material padatan tersuspensi di perairan berubah begitu saat surut di mana volume air laut berkurang. Sesuai dengan pernyataan Mulyanto (2007), bahwa air pasang akan membawa sedimen dari laut ke dalam muara sungai untuk diendapkan di dalam muara dan menambah endapan yang sudah ada pada area tersebut.

\section{KESIMPULAN}

Berdasarkan hasil penelitian Studi Pola Sebaran Material Padatan Tersuspensi di Sungai Jajar Demak Kabupaten Demak Provinsi Jawa tengah, dapat disimpulkan bahwa persebaran konsentrasi MPT bergerak menyebar dari muara sungai menju ke arah laut lepas. Dengan nilai persebaran konsentrasi MPT tertinggi berada pada kedalaman 0.8 . Serta pola distribusi material padatan tersuspensi dipengaruhi oleh pergerakan arus. Dengan nilai konsentrasi cukup tinggi di muara sungai, yaitu pada stasiun 2 dan nilai konsentrasi material padatan tersuspensi semakin berkurang kearah laut lepas yaitu pada stasiun 7 .

\section{DAFTAR PUSTAKA}

Anasiru, T. 2005. Analisis Perubahan Kecepatan Aliran Pada Muara Sungai Palu. Jurnal SMARTek. 3(2) : $101-112$

Azis, M. F. 2006. Gerak Air di Laut. Jurnal Oseana., 21(4) : 9 - 21.

Badan Standarisasi Nasional. 2004. SNI 06-6989.3-2004 Cara Uji Padatan Tersuspensi Total (Total Suspendel Solid, TSS) Secara Gravimetri. BSN, Jakarta.

Djaja R. 1989. Pengamatan Pasang Surut Laut untuk Penentuan Datum Ketinggian. LIPI. Jakarta

Hadi, S dan I. M. Radjawane. 2009. Arus Laut. Program Studi Oseanografi ITB, Bandung.

Hamid, M. 2005. Ilmu Pengetahuan Sosial-Geografi Direktorat Pendidikan Lanjutan Pertama, Jakarta.

Poerbandono dan E. Djunasjah. 2005. Survei Hidrografi. Refika Aditama, Bandung.

Sarjono, A. 2009. Analisa Kandungan Logam Berat Cd, Pb, dan Hg Pada Air dan Sedimen di Perairan Kamal Muara, Jakarta Utara. Departemen ManajemenSumberdaya Perairan. Skripsi. Fakultas Perikanan dan Ilmu Kelautan Institut Pertanian, Bogor.

Solihuddin, T. 2009. Pemanfaatan Citra Landsat Multitemporal untuk Memantau Konsentrasi Total Padatan Tersuspensi di Perairan Delta Cimanuk, Jawa Barat. Buletin Geologi Tata Lingkungan., 19 (3) : 107 116.

Solihuddin, T, E. M. Sari, dan G. Kusumah. 2011. Prediksi Laju Sedimentasi di Perairan Pemangkat, Sambas, Kalimantan Barat Menggunakan MetodePemodelan. Buletin Geolodi Tata Lingkungan. 21(3) : 117126.

Sugiyono. 2009. Metode Penelitian Kuantitatif Kualitatif dan R\&D. CV. Alfabeta : Manado. 